\title{
Um caso de leucismo em pardal, Passer domesticus (Linnaeus, 1758) em uma ilha do rio São Francisco, nordeste do Brasil
}

\author{
Leonardo Barros Ribeiro ${ }^{1,2 *}$ \\ Melissa Gogliath ${ }^{3}$ \\ ${ }^{1}$ Universidade Federal do Vale do São Francisco, Campus Ciências Agrárias \\ Colegiado de Ciências Biológicas, CEP 56300-990, Petrolina - PE, Brasil \\ ${ }^{2}$ Centro de Conservação e Manejo de Fauna da Caatinga \\ ${ }^{3} \mathrm{PPG}$ em Psicobiologia, Centro de Biociências, Universidade Federal do Rio Grande do Norte \\ CEP 59078-970, Natal - RN, Brasil \\ *Autor para correspondência \\ leonardo.ribeiro@univasf.edu.br
}

Submetido em 08/07/2011

Aceito para publicação em 10/10/2011

\section{Resumo}

O leucismo em aves é uma anomalia genética caracterizada pela ausência total de melanina em algumas ou em todas as penas, porém, ao contrário do albinismo, as outras partes do corpo, tais como olhos, bico e tarsos permanecem com a coloração típica da espécie. O pardal Passer domesticus é uma ave nativa da Europa, Ásia e norte da África e foi introduzido na América do Norte, América do Sul, África do Sul, Austrália e Nova Zelândia. Atualmente, é a espécie de ave com a maior distribuição geográfica. Relatamos, aqui, o registro de um indivíduo leucístico de Passer domesticus na ilha do Rodeadouro, rio São Francisco, nordeste do Brasil.

Palavras-chave: Anomalia genética, Aves, Ilha fluvial, Passeridae, Passeriformes

\section{Abstract}

A case of leucism in House Sparrow, Passer domesticus (Linnaeus, 1758) in an island of São Francisco river, northeastern Brazil. Leucism in birds is a genetic disorder characterized by the total absence of melanin in some or all feathers, but unlike albinism, the other body parts, such as eyes, beak, and tarsi remain with the typical color of the species. The House Sparrow Passer domesticus is a bird native from Europe, Asia, and North Africa. It has been introduced in North America, South America, South Africa, Australia, and New Zealand. Currently, it is the bird species with the largest geographical range. Here, we report the record of a leucistic specimen of Passer domesticus from Rodeadouro island, São Francisco river, northeastern Brazil.

Key words: Birds, Genetic disorder, Passeridae, Passeriformes, River island 
Em aves, o leucismo é caracterizado pela ausência total de melanina em algumas ou em todas as penas como resultado de alelos mutantes (BENSCH et al., 2000) ou de divergências na expressão de genes que acabam impedindo a pigmentação e o desenvolvimento da pena (MØLLER; MOUSSAEU, 2001). As outras partes do corpo, como olhos, bico e tarsos permanecem com a coloração típica da espécie (NEMÉSIO, 1998; 1999; GRILLI et al., 2006; VAN GROUW, 2006). Em alguns casos, as aves leucísticas podem mostrar diminuição da pigmentação no bico, pernas e em algumas partes do olho, contudo diferem de um albino, porque mostram pupila escura, uma vez que pigmentos na parte posterior do globo ocular estão presentes (VAN GROUW, 2006). O leucismo parece ocorrer em uma frequência inferior a $1 \%$ (BENSCH et al., 2000), porém é ainda mais frequente do que o albinismo, especialmente em aves adultas (VAN GROUW, 2006). Os relatos iniciais de leucismo em aves tiveram maior destaque para espécies criadas em cativeiro, em especial das famílias Psittacidae e Emberizidae (NEMÉSIO, 1999; 2001).

O pardal Passer domesticus (Passeridae) é uma ave nativa da Europa, Ásia e norte da África e foi introduzido na América do Norte, América do Sul, África do Sul, Austrália e Nova Zelândia (SICK, 1997;
GUILHERME, 2000). Atualmente, é a espécie de ave com a maior distribuição geográfica (GUILHERME, 2000). Vivem comumente em bandos, fortemente associados a habitações humanas (LOWTHER; CINK, 1992). Neste trabalho, informamos o registro de um indivíduo leucístico de $P$. domesticus para uma ilha do rio São Francisco em Petrolina, Pernambuco.

Em 23 de junho de 2011 as 15 h00min, um pardal de sexo não determinado apresentando leucismo parcial foi observado na ilha do Rodeadouro à margem do rio São Francisco voltada para o município de Petrolina, Pernambuco ( $9^{\circ} 27^{\prime} 55^{\prime}$ 'S, 40³4'45”W).

$\mathrm{O}$ indivíduo foi registrado no momento em que bebia água na margem do rio. Sua plumagem era quase toda branca, apresentando a coloração típica da espécie restrita às rêmiges e retrizes. Apesar da despigmentação no bico e nos tarsos, inequivocamente os olhos pretos confirmam o leucismo parcial (Figura 1).

Registros anteriores de pardais leucísticos e albinos são conhecidos para o Distrito Federal e municípios dos estados de Minas Gerais, Rio de Janeiro, São Paulo, Bahia, Pernambuco e Santa Catarina (LORDELLO, 1951; SICK, 1959; PEREIRA et al., 2008). Nestes estudos, os indivíduos com leucismo parcial apresentavam

FIGURA 1: Passer domesticus leucístico, mostrando coloração típica da espécie restrita às rêmiges, retrizes e olhos, e despigmentação no bico e tarsos.

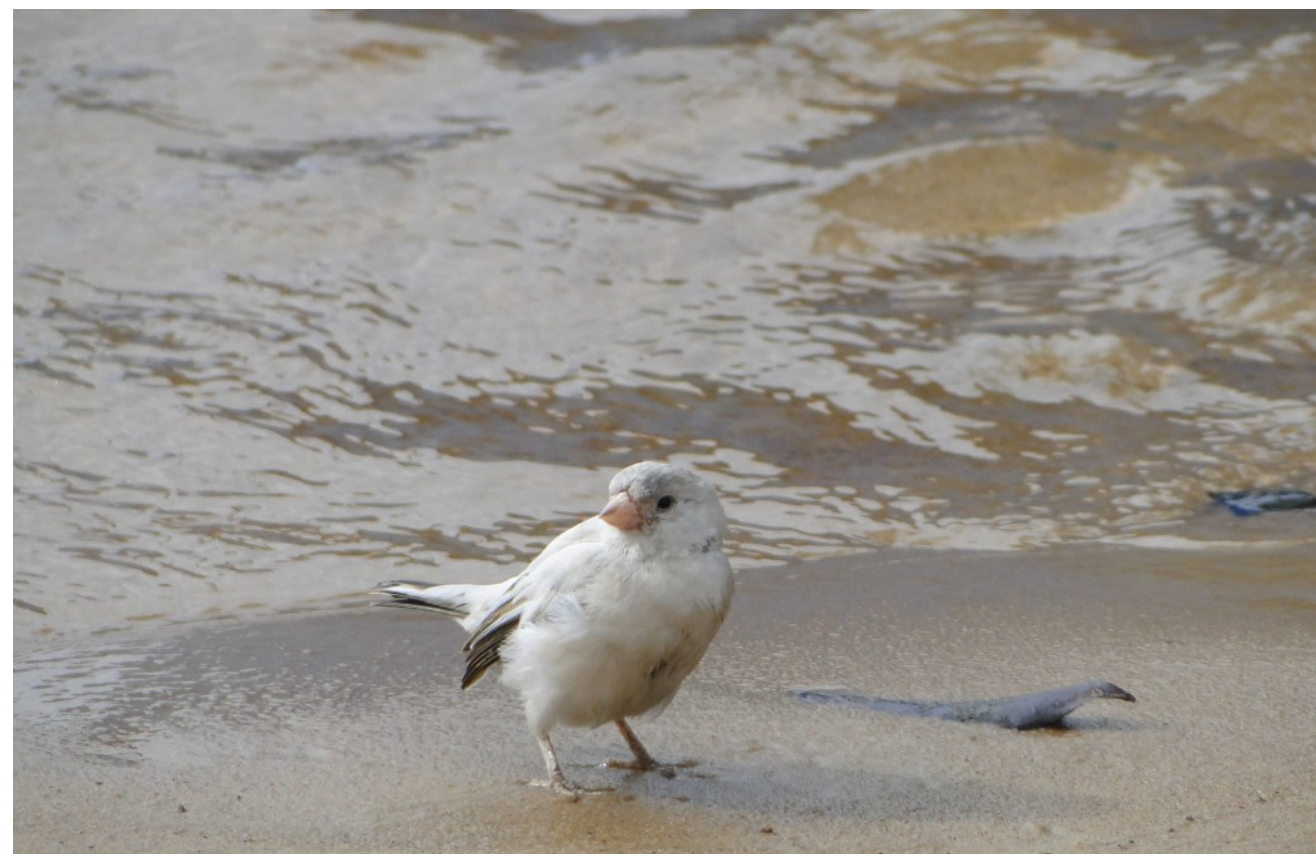


quantidade variável de penas do dorso, da cauda, das asas e das coberteiras das asas com cor branca. Os indivíduos com leucismo total possuíam olhos pretos, e os albinos, olhos avermelhados e despigmentação no bico e tarsos. O leucismo parcial identificado para o pardal da ilha do Rodeadouro apresentou uma similaridade adicional com o albinismo devido à despigmentação das partes nuas (bico e tarsos). Além dos casos supracitados, há ocorrências descritas na literatura, de vários tons de cores em pardais originados a partir de mutações, tais como lutina, canela, amarelo-claro, pastel e opala (SICK, 1997; VERHOEFVERHALLEN, 2000; PEREIRA et al., 2008).

Plumagens diferentes dos padrões normais de coloração também já foram documentadas para várias outras espécies de aves, tanto em populações naturais quanto em indivíduos cativos (NERO, 1954; GROSS, 1965). Não obstante, em função de uma maior oportunidade de registro, grande parte dos casos publicados sobre aves com plumagem anormal envolve espécies com algum tipo de associação com o homem, seja vivendo em ambientes antrópicos e/ ou periantrópicos, tais como Columbina talpacoti (MALLET-RODRIGUES, 1995), Melopsittacus undulatus (NEMÉSIO, 1998), Vanellus chilensis (CESTARI; COSTA, 2007; FRANZ; FLECK, 2009), Coragyps atratus (SOUSA et al., 2009) e Athene cunicularia (NOGUEIRA; ALVES, 2011).

Em relação à interação com os demais pardais, notamos que o indivíduo leucístico se manteve sempre afastado ou na periferia do bando. Comportamentos semelhantes foram registrados por Pereira et al. (2008) em fêmeas de $P$. domesticus com plumagens canela e albina. Apesar disso, o comportamento de corte a pardais fêmeas com plumagens aberrantes já foi documentado (PEREIRA et al. 2008), existindo também relatos de outras espécies com estas anomalias que chegaram a nidificar e ter sucesso reprodutivo (e.g., BENSCH et al., 2000; MALLET-RODRIGUES, 2001).

De acordo com Santos (1981) e Collins (2003), o tempo de vida de aves com leucismo e albinismo na natureza é relativamente reduzido se comparado às aves de coloração normal, visto que são procuradas com mais frequência pelos predadores devido a sua cor atraente e distinta.

\section{Agradecimentos}

A Marco Antônio Manhães, pela leitura crítica do manuscrito, e a um revisor anônimo, pelas valiosas sugestões.

\section{Referências}

BENSCH, S.; HANSSON, B.; HASSELDUIST, D.; NIELSEN, B. Partial albinism in a semi-isolated population of Great Reed Warblers. Hereditas, Lund, v. 133, p. 167-170, 2000.

CESTARI, C.; COSTA, T. V. V. A case of leucism in Southern Lapwing (Vanellus chilensis) in the Pantanal, Brazil. Boletín SAO, Medellín, v. 17, n. 2, p. 145-147, 2007.

COLLINS, C. T. A leucistic Willet in California. Western Birds, San Diego, v. 34, p. 118-119, 2003.

FRANZ, I.; FLECK, R. Dois casos de leucismo em quero-quero Vanellus chilensis (Molina, 1782) no sul do Brasil. Biotemas, Florianópolis, v. 22, n. 1, p. 161-164, 2009.

GUILHERME, E. On the arrival of the House Sparrow (Passer domesticus) in southwestern Brazilian Amazon. Melopsittacus, Belo Horizonte, v. 3, n. 4, p. 171-172, 2000.

GRILLI, P. G.; MOSCHIONE, F. N.; BURGOS, F. G. Leucismo parcial en pepitero de collar Saltator aurantiirostris en Santa Bárbara, Jujuy, Argentina. Cotinga, Sandy, v. 25, p. 89-90, 2006.

GROSS, A. O. The incidence of albinism in North American birds. Bird-Banding, Columbus, v. 36, n. 2, p. 67-71, 1965.

MALLET-RODRIGUES, F. Um registro de albinismo em Columbina talpacoti (Temincki, 1811) para o Rio de Janeiro. Atualidades Ornitológicas, Ivaiporã, n. 64, p. 12, 1995.

LORDELLO, L. G. E. Passer domesticus albino e considerações acerca de algumas anomalias de plumagens verificadas em aves do Brasil. Dusenia, Curitiba, v. 2, n. 6, p. 361-364, 1951.

LOWTHER, P. E.; CINK, C. L. "House Sparrow (Passer domesticus)." In: POOLE, A.; STETTENHEIM, P.; GILL, F. (Ed.). The birds of North America, n. 12. Washington: The Academy of Natural Sciences, Philadelphia, Pennsylvania; The American Ornithologists' Union, 1992. p. 1-20.

MØLleR, A. P.; MOUSSAEU, T. A. Albinism and phenotype of barn swallows (Hirundo rustica) from Chernobyl. Evolution, Lancaster, v. 55, p. 2097-2104, 2001.

NEMÉSIO, A. Herança de cores no periquito-australiano Melopsittacus undulatus. Belo Horizonte: Melopsittacus Publicações Científicas, 1998. 168 p.

NEMÉSIO, A. Plumagens aberrantes em Psittacidae neotropicais - uma revisão. Melopsittacus, Belo Horizonte, v. 2, n. 2/4, p. 51 58, 1999.

NEMÉSIO, A. Plumagens aberrantes em Emberizidae neotropicais. Tangara, Belo Horizonte, v. 1, n. 1, p. 39-47, 2001.

NERO, R. W. Plumage aberrations of the Redwing Agelaius phoeniceus. The Auk, Washington, v. 71, p. 137-155, 1954.

NOGUEIRA, D. M.; ALVES, M. A. S. A case of leucism in the burrowing owl Athene cunicularia (Aves: Strigiformes) with 
confirmation of species identity using cytogenetic analysis. Zoologia, Curitiba, v. 28, n. 1, p. 53-57, 2011.

PEREIRA, G. A.; DANTAS, S. M.; PERIQUITO, M. C.; BRITO, M. T.; FARIAS, G. B.; MIGUEL, M.; RIZZO, C. A.; VIANA, R. E.; COELHO, G.; SILVA, M. F. Registros de algumas mutações em pardais (Passer domesticus) no Brasil. Atualidades Ornitológicas, Ivaiporã, n. 146, p. 45-47, 2008.

SANTOS, T. Variantes de plumajes y malformaciones en Turdus spp. Ardeola, Madrid, v. 28, p. 133-138, 1981.

SICK, H. A invasão da América Latina pelo pardal, Passer domesticus Linnaeus 1758, com referência especial ao Brasil (Ploceidae, Aves). Boletim do Museu Nacional, Nova Série, Zoologia, Rio de Janeiro, v. 207, p. 1-31, 1959.
SICK, H. Ornitologia brasileira. Rio de Janeiro: Nova Fronteira, 1997. $912 \mathrm{p}$

SOUSA, M. C.; COSTA, J. P. M.; SILVA, R. A. C. Albinismo em Coragyps atratus (Cathartiformes: Cathartidae) no estado de Sergipe. Atualidades Ornitológicas, Ivaiporã, n. 150, p. 22-23, 2009.

VAN GROUW, H. Not every white bird is an albino: sense and nonsense about colour aberrations in birds. Dutch Birding, Santpoort-Zuid, v. 28, p. 79-89, 2006.

VERHOEF-VERHALLEN, E. Enciclopédia das aves de gaiola. Florianópolis: Livros e Livros, 2000. 312 p. 